\title{
Detecting Defects in Photovoltaic Cells and Panels With the Help of Time-Resolved Thermography Under Outdoor Environmental Conditions
}

\author{
Christian Schuss*, Kari Remes*, Kimmo Leppänen ${ }^{\dagger}$, Juha Saarela*, Tapio Fabritius* $^{*}$, Bernd Eichberger ${ }^{\ddagger}$, \\ and Timo Rahkonen ${ }^{\S}$ \\ ${ }^{*}$ Optoelectronics and Measurement Techniques (OPEM) Research Unit, University of Oulu, Finland; \\ email: christian.schuss, kari.remes, juha.saarela, tapio.fabritius@oulu.fi \\ ${ }^{\dagger}$ Mettler-Toledo GmbH, SBU AutoChem, Switzerland; email: kimmo.leppanen@mt.com \\ ${ }^{\ddagger}$ Institute of Electronic Sensor Systems, Graz University of Technology, Austria; email: bernd.eichberger@tugraz.at \\ ${ }^{\S}$ Circuits and Systems (CAS) Research Unit, University of Oulu, Finland; email: timo.rahkonen@oulu.fi
}

\begin{abstract}
This paper investigates defects in photovoltaic (PV) cell and panels, in particular, the size and location of defects. We concentrate on characterising photovoltaics under outdoor environmental conditions with the help of synchronized thermography (ST) and time-resolved thermography (TRT). Infrared (IR) images are obtained under changing solar radiation levels and moderate wind speeds with the help of a portable IR-camera. We demonstrate that IR-images obtained outdoors by ST and TRT provide the same information in the same accuracy as IR-images recorded indoors. We elaborate the differences in parameters such as measurement time and region-of-interest (ROI) which need to be adjusted when moving from indoor to outdoor environments. Our technique allows maintenance staff to carry out measurements on the site of a PV power plant to identify PV panels with defects in an easy way.

Index Terms - defect, indoor environment, infrared, outdoor environment, photovoltaic cell, photovoltaic panel, solar energy, synchronized thermography, time-resolved thermography.
\end{abstract}

\section{INTRODUCTION}

Forecasts show that world's energy consumption will increase by $56 \%$ between 2010 and 2040 . Over the same time period, it is estimated that global energy-related carbon dioxide emissions will increase to 45 billion metric tons in 2040, a 46\% increase from 2010 [1]. Solar energy is the most promising energy resource to counteract these negative future projections for humanity and to substitute non-renewable energy resources such as coal, oil, gas and nuclear power (COGN) energy sources [2], [3].

However, the potential energy of photovoltaics depends not only on the available irradiation, but can also decrease due to aging and different types of defects over time. It is worth noting that a defect in single PV cell has an impact on the output performance of the whole PV panel and, therefore, on the performance of the entire PV plant [4]-[7]. Hence, it is important to detect faults and defects in PV panels. Moreover, a PV panel which is defect should be replaced by maintenance staff to improve the performance of a PV power plant [8].

Commonly, the performance of PV panels is characterised with the help of electrical measurements to obtain the characteristic Current-Voltage $(I-V)$ curve of PV panels [9]-[11].
However, electrical measurements can only measure the $I$ $V$ curve of individual PV panels, but not of an array of a PV power plant. Thus, PV panels must be disconnected from the array for carrying out measurements. These circumstances result in longer measurement times to identify PV panels with defects. Hence, infrared thermal (IRT) imaging techniques gained significantly interest to be used by maintenance staff on the site of the PV power plant to verify the performance of PV panels [12].

Generally speaking, optical measurement techniques such as lock-in thermography (LIT), electroluminescence (EL) imaging, photoluminescence (PL) imaging, synchronized thermography (ST), time-resolved thermography (TRT) and other IRT techniques are developed for measurements under indoor environmental conditions [13]-[17]. Recently, efforts have been made also to use IRT techniques for characterising PV panels under outdoor environmental conditions to detect defects in PV panels [18]-[20]. In contrast to measurements indoors, outdoors, a significant amount of background irradiation can be present during the measurement.

The background irradiation as well as other factors can have various impacts on the result of the measurement, in particular the accuracy of the measurement. As an example, Akram et al. [18] report in their work that experiments conducted on PV panels with defects do not result in the same information. More precisely, IR-images obtained under outdoor environmental conditions show fewer or not all defects in PV panels in comparison to indoor measurements [18]. Similarly, Teubner et al. [19] report that weather conditions can affect the results of IR thermography. In their work, for measurements outdoors, steady-sate conditions are preferred in which the solar radiation level does not change within a certain period of time [19].

In this paper, we wish to utilise TRT, developed in previous research [17], for detecting defects in PV panels under outdoor environmental conditions. As in the available literature, we wish to compare our results obtained outdoors with the results of measurements obtained indoors (i.e. laboratory conditions) 
and electrical measurements. We also consider different circumstances, as reported in the available literature, which have an impact on the accuracy of the measurement, such as frequent changes in the available weather conditions, in particular the available irradiation.

In previous research [17], we used a portable IR-camera (i.e. Flir ONE) which can be attached to an Android smartphone for recording IR-images of PV panels. We demonstrated that a portable IR-camera is capable of obtaining IR-images which are similar to the IR-images obtained with an IR-camera for laboratory measurements such as the Optris PI 640. However, it is worth noting that the costs of the Flir ONE are much lower in comparison to the Optris PI 640 [17]. Furthermore, a portable IR-camera can be easily used by maintenance staff for analysing PV panels within PV power plants.

\section{BACKGROUND OF THE RESARCH}

TRT is based on ST, which was originally developed for the characterisation of thin films [16]. In contrast to illuminated LIT (ILIT) and PL imaging, ST and therefore TRT does not require uniform illumination of the device under test (DUT). These circumstances help as it is expected that under outdoor environmental conditions the irradiation on top of the PV panel will be similar but not entirely uniform. Furthermore, under outdoor environmental conditions, it is expected that the solar radiation level $(\lambda)$ changes during the duration of the measurement. Especially if the sky is overcast, the solar radiation level can change frequently between shadow and direct sunlight.

In previous research, we used the Flir ONE with a Samsung Galaxy S4 (GT-I9506) smartphone [17]. Due to software limitations in the Flir mobile application, we were not able to change parameters such as the minimum and maximum value for the temperature scale within video recordings. Thus, we fixed the temperature scale in the mobile application and then streamed as well as recorded the screen of the smartphone to a computer on which the streamed video was recorded. In this paper, we use the Flir ONE PRO (with a USB-C connector) and a Nokia 8 (TA-1004) smartphone. Running on Android 9.0 (Pie), the Flir mobile application allows advanced features including the option to fix the temperature scale within video recordings. Hence, streaming and recording externally is not anymore required.

\section{EXPERIMENTAL SETUP AND PROCEDURE}

\section{A. Setup under Outdoor Environmental Conditions}

Fig. 1 shows the basic measurement setup of TRT. As seen in Fig. 1, an external power supply is used to forward bias and, thereby, heat up PV panels. Generally speaking, heating up PV panels is a common procedure. If PV panels are covered by snow or ice, then panels are biased forward to melt the snow or ice covering the protection glass of PV panels, allowing them again to generate electricity. When forward biasing PV panels, temperature differences can be obtained in IR-images. For example, if a hairline crack is present in a PV cell the defect part of the PV cell is physically disconnected from the

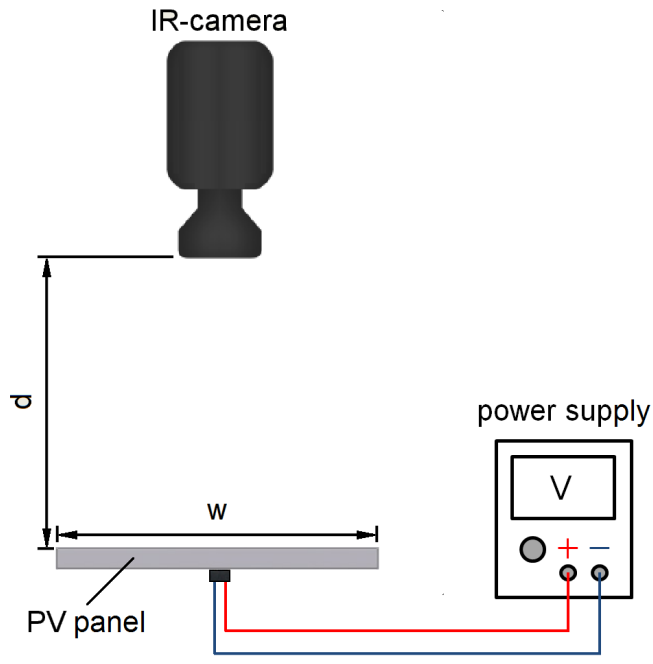

Fig. 1: Schematic of TRT for measurement outdoors

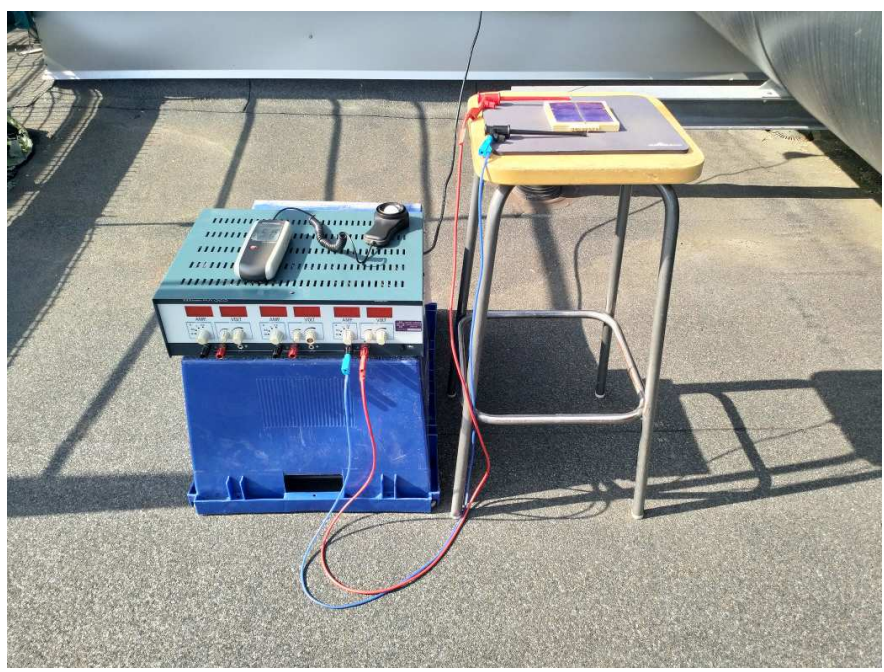

Fig. 2: TRT measurement setup

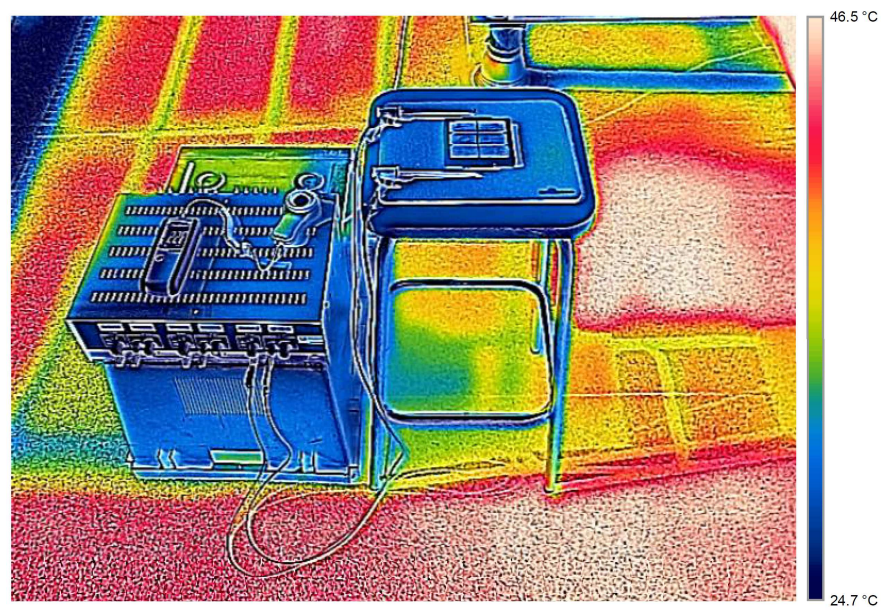

Fig. 3: Thermal image of the TRT measurement setup 
rest of the PV cell. As a result, when the PV cell is forwardbiased, the defect part does not conduct current and, thus, does not heat up. Moreover, due to the hairline crack, the remaining part of the PV cell in which no defect is present conducts more current and, hence, heats up more than non-defect PV cells [16].

Fig. 2 shows the TRT measurement setup on the roof of the University of Oulu in the City of Oulu, Finland. Measurements were conducted in August when the ambient temperature was $14{ }^{\circ} \mathrm{C}$, wind speed $7 \mathrm{~m} / \mathrm{s}$, gust speed $10 \mathrm{~m} / \mathrm{s}$, and the solar radiation level was frequently varying between 100 and 500 $\mathrm{W} / \mathrm{m}^{2}$ (horizontal level). However, as seen on the right-hand side of Fig. 2, the measurement setup was located next to the cooling pipes of the university's air conditioning system. In addition, even though the ambient temperature was $14^{\circ} \mathrm{C}$, the asphalt shingle type roof reached a temperature of about 50 ${ }^{\circ} \mathrm{C}$ as shown in the thermal image of the TRT measurement setup in Fig. 3.

The background temperatures have an impact on the settings of the IR-camera's temperture scale. In contrast, indoors, a narrower temperature scale can be used for the IR-camera in comparison to outdoors. Furthermore, due to potential reflections from the DUT, the IR-camera needs to be slightly tilted when recording IR-images. As a result, the regionof-interest (ROI) is affected, in other words, the available resolution of the IR-image for analysing the DUT [16]. The Flir ONE Pro can record IR-images as a video in a resolution of $1440 \times 1080$ pixels with 9 frames per second.

\section{B. Experimental Results}

In this research, we considered the potential practical usability of TRT for characterising PV panels under outdoor environmental conditions. For measurement indoors [17], as seen in the schematic of the measurement setup in Fig. 1, we used a small construction for installing the IR-camera under an optimal distance $(d)$ from the DUT in order to maximise the use of the resolution of the IR-camera. However, outdoors, in particular to record IR-images of PV panels installed on the roof of buildings, it can be challenging to use a structure for installing the IR-camera in a certain distance from the DUT. Most likely, maintenance staff will just hold a IR-camera in their hands when recording images.

Hence, we decided also to hold the IR-camera in the hand while recording IR-images within experiments. It is worth noting that these circumstances have an impact on the IRimage recording. Not only will a person move naturally during the recording, also moderate wind and gust speeds will affect the position of the IR-camera. Fig. 4 shows the temperature distribution of sample number 2, which was measured in previous research indoors with ST [16]. The sample was made out of three PV cells, which were connected in series. Table I summarises the available data of one PV cell provided by the PV manufacturer Motech Industries, Inc. As seen in Fig. $4 \mathrm{a}$, in the beginning of the measurement, a strong gust speed affected the position of the IR-camera and, thus, needed to

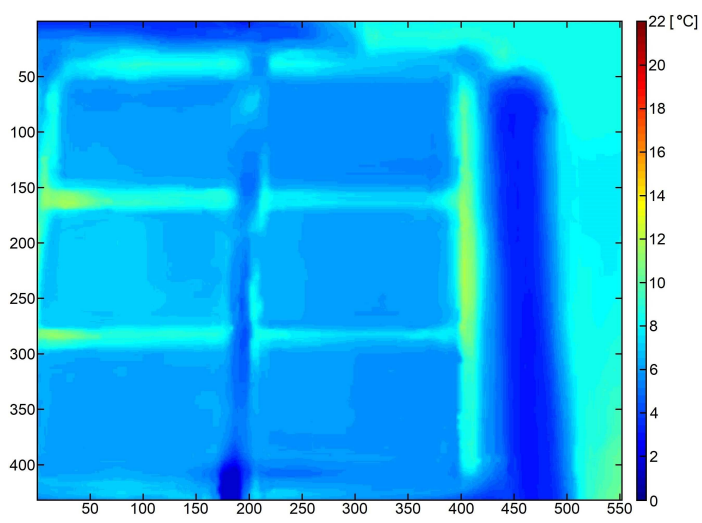

(a) $t=2.8 \mathrm{~s}$ (frame number $=25$ )

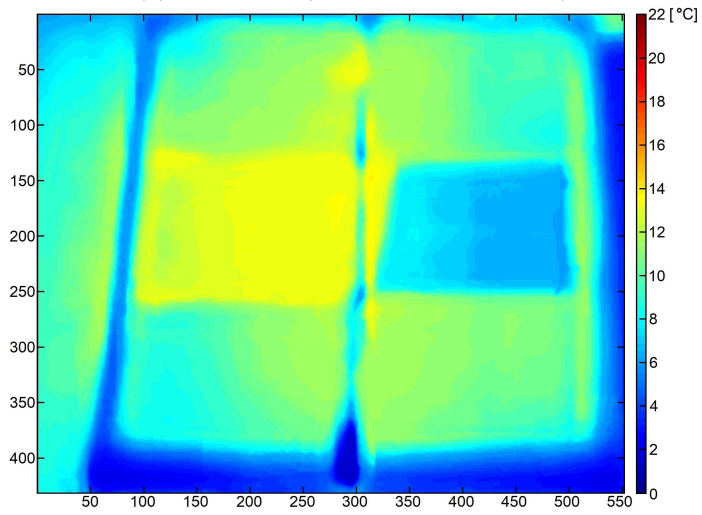

(b) $t=9.2 \mathrm{~s}($ frame number $=83$ )

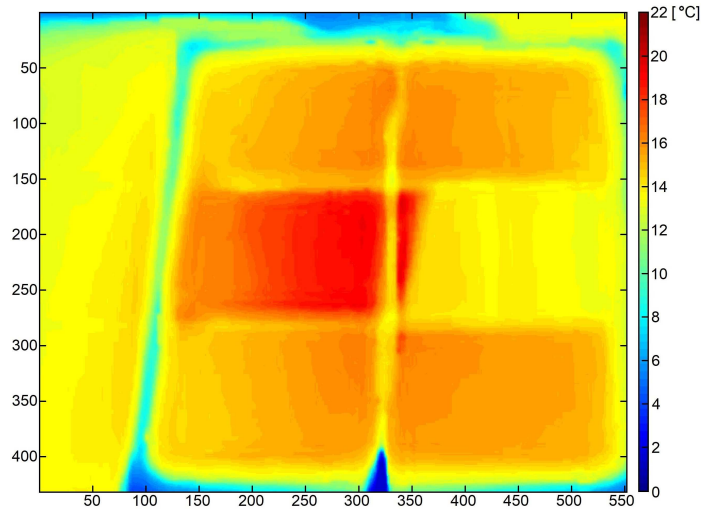

(c) $t=22.1 \mathrm{~s}($ frame number $=199)$

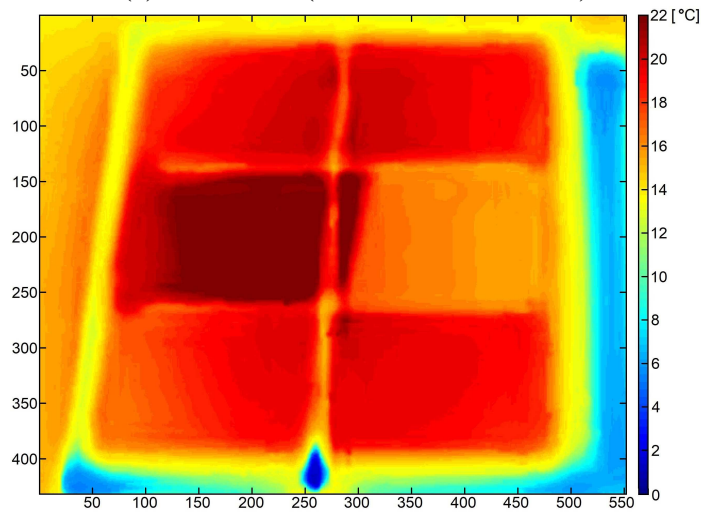

(d) $t=47.9 \mathrm{~s}($ frame number $=431)$

Fig. 4: Temperature distribution of sample 2 without glass 
be readjusted towards the right-hand side. Due to potential movements of the IR-camera, the ROI needs to be widened.

TABLE I: Data of one PV cell from Motech Industries, Inc.

\begin{tabular}{|c|c|}
\hline Parameter & Value \\
\hline $\mathrm{P}_{\mathrm{mpp}}[\mathrm{W}]$ & 0.33 \\
\hline $\mathrm{V}_{\mathrm{oc}}[\mathrm{V}]$ & 0.61 \\
\hline $\mathrm{I}_{\mathrm{sc}}[\mathrm{A}]$ & 0.69 \\
\hline $\mathrm{V}_{\mathrm{mpp}}[\mathrm{V}]$ & 0.51 \\
\hline $\mathrm{I}_{\mathrm{mpp}}[\mathrm{A}]$ & 0.65 \\
\hline length [mm] & 78 \\
\hline width [mm] & 26 \\
\hline
\end{tabular}

AM1.5; $\lambda=1000 \mathrm{~W} / \mathrm{m}^{2} ; T_{c}=25^{\circ} \mathrm{C} ;$ standard test conditions (STC)

In experiments, first, the DUT was left in idle outdoors. In this way, we ensured that the DUT was given enough time to reach a constant temperature based on the given ambient conditions. Then, as in previous research [16], [17], [21], the external power supply was connected to the DUT and powered on at the same time when recording IR-images started. Hence, each frame recorded with the help of TRT, shows the progression of the heating process of the DUT. The aim of this research was to verify the potential impact of outdoor environmental conditions on the progression of the heating process.

Without protection glass, it is easy to see the hairline crack in the PV cell located in the middle. The Flir One Pro allows to overlay a visual image over a thermal image, as seen in Fig. 3. However, for the IR-image recording, this functionality must be deactivated. Videos were recorded in grey-style to allow processing videos in MATLAB and, thereby, identifying the size of potential defects in PV cells. As seen in Fig. $4 \mathrm{~b}-4 \mathrm{~d}$, the temperature scale ranging from 0 to $22{ }^{\circ} \mathrm{C}$ is much larger than in the measurement indoors (i.e. 0 to $8{ }^{\circ} \mathrm{C}$ [16]). In [21], we present the procedure to estimate the size of a defect in a PV cell based on temperature differences obtained with TRT. The estimated size of the defect area and, thereby, the estimated loss in output power $(\Delta P)$ within TRT measurements under outdoor environmental conditions was $47.2 \% \pm 1.5 \%$ and correlated with the results obtained under indoor environmental conditions and with electrical measurements.

Fig. 5 shows the temperature distribution of PV panel number 1 which was characterised in previous research with the help of TRT indoors [17]. Table II summarises the available data of the PV panel DSP-5P provided by the PV manufacturer [lux.pro] Corporation. Indoors, a minimum heating time $\left(t_{\min }\right)$ of $30 \mathrm{~s}$ was needed. However, outdoors, after $t=30 \mathrm{~s}$, temperature differences are just starting to form and have not yet fully developed. After about two minutes, as seen in Fig. $5 \mathrm{~b}$ at $t=124.6 \mathrm{~s}$ (frame number 1,121), the hot spot in the middle of the PV panel and the cold spot on the righthand side of the PV panel become visible. In Fig. $5 \mathrm{~d}$ at $t$ $=209.6 \mathrm{~s}$ (frame number 1,886), the defect can be detected in MATLAB, but still with a notable error in the estimated size of the defected area. Hence, the measurement needs to be continued until the total measurement time is about 10

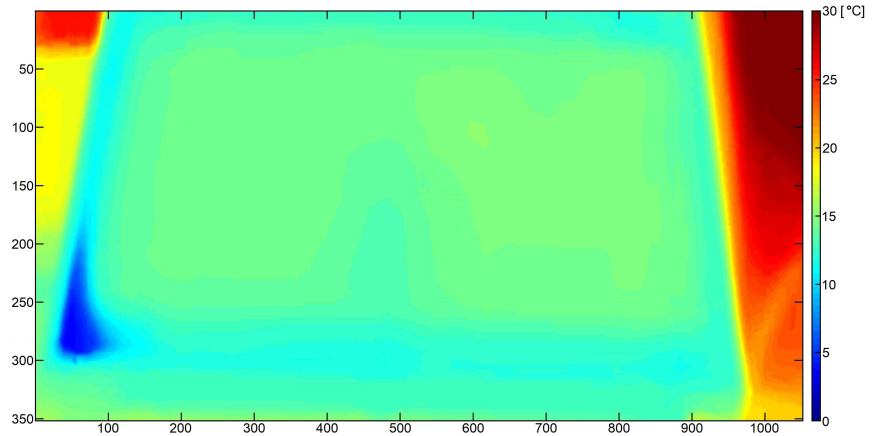

(a) $t=11.1 \mathrm{~s}$ (frame number $=100)$

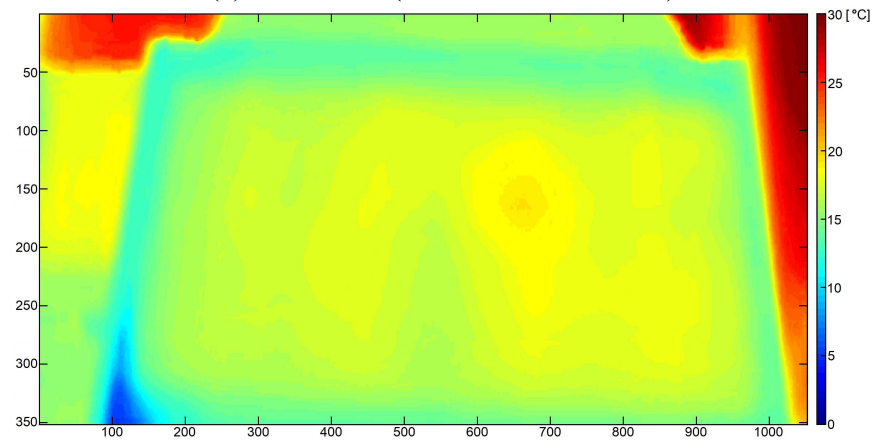

(b) $t=124.6 \mathrm{~s}$ (frame number $=1,121$ )

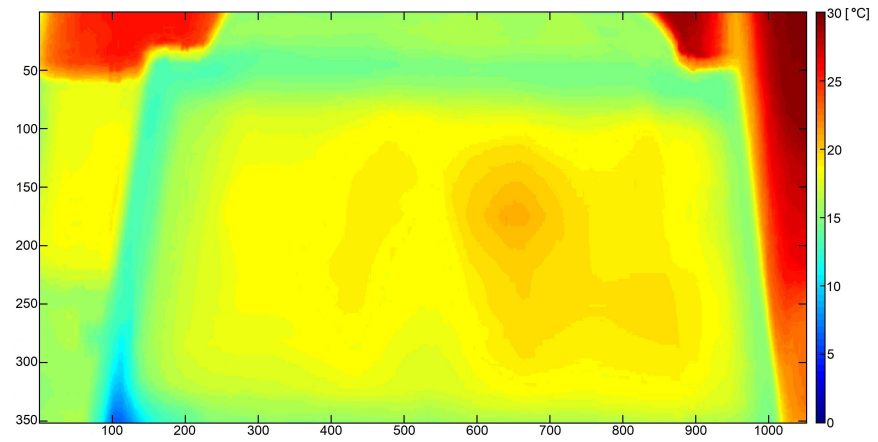

(c) $t=152.9 \mathrm{~s}($ frame number $=1,376)$

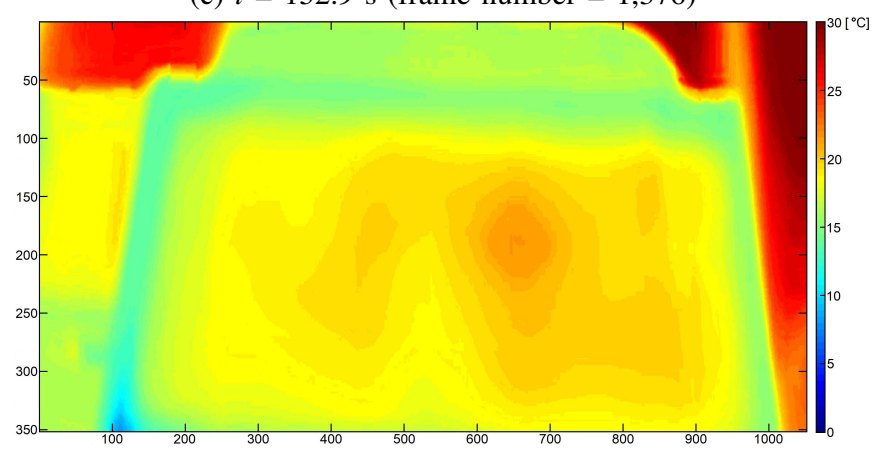

(d) $t=209.6 \mathrm{~s}$ (frame number $=1,886$ )

Fig. 5: Temperature distribution of PV panel 1

minutes in order to determine the precise size of the defect under outdoor environmental conditions.

In practice, it is unrealistic that maintaence staff will record IR-images on a continous basis for such a long period of time. Hence, we analysed the change in the temperature differences 
TABLE II: Data of the [lux.pro] DSP-5P

\begin{tabular}{|c|c|}
\hline Parameter & Value \\
\hline $\mathrm{P}_{\text {mpp }}[\mathrm{W}]$ & 5.00 \\
\hline $\mathrm{V}_{\text {oc }}[\mathrm{V}]$ & 11.25 \\
\hline $\mathrm{I}_{\mathrm{sc}}[\mathrm{A}]$ & 0.81 \\
\hline $\mathrm{V}_{\mathrm{mpp}}[\mathrm{V}]$ & 9.00 \\
\hline $\mathrm{I}_{\mathrm{mpp}}[\mathrm{A}]$ & 0.56 \\
\hline length [mm] & 350 \\
\hline width [mm] & 174 \\
\hline height [mm] & 19 \\
\hline
\end{tabular}

AM1.5; $\lambda=1000 \mathrm{~W} / \mathrm{m}^{2} ; T_{c}=25{ }^{\circ} \mathrm{C} ;$ standard test conditions (STC)

in the IR-images recorded with TRT. Fig. 6 shows the median temperature over the first 200 seconds of the measurement. As in previous research [17], the progression of the median temperature is constant on a linear basis. Hence, as in the case with ST [16], the DUT needs to be forward-biased for a sufficient time, before an IR-image is taken. In the meantime, it is not necessary to take IR-images.

Indoors, when carrying out measurements with the help of TRT, the ambient temperature (i.e. room temperature) was constant throughout the duration of the measurement. In addition, as measurements were carried out in a dark environment, $\lambda$ $\approx 0 \mathrm{Wm} /{ }^{2}$. Generally speaking, under indoor environmental conditions, it is possible to control the amount of light in the background and regulate the ambient temperature. However, under outdoor environmental conditions, as elaborated in [19], it is not possible to influence the given ambient conditions. That is why the impact of outdoor environmental conditions have to be examined and, if necessary, taken into account.

While Fig. 6 shows the median temperature and, therefore, the progression of the heating process of the DUT, Fig. 7 presents the progress of a reference temperature outside the ROI. The reference temperature was taken from the measurement setup on which the DUT was placed. In contrast to other approaches such as [19], which require a reference sample, it is worth noting that for TRT a reference is not needed. Thus, the temperature was only taken as a reference to get an understanding whether the temperature differences observed in IR-images are caused by forward biasing the PV panel with the external power supply or by changes in the ambient conditions.

As seen in Fig. 7, over the first 200 seconds of the measurement, the reference temperature varied between 29.7 and $30.4{ }^{\circ} \mathrm{C}$. Even though, the solar radiation level $(\lambda)$ changes and wind as well as gust speeds are present, the ambient temperature remains relatively constant. Hence, it can be said that the temperature progression observed in the DUT is introduced by the TRT and not caused by changes in the given ambient conditions. However, depending on the actual circumstances, it can be the case the ambient conditions can have minor effects on the DUT.

Fig. 8 shows the thermal image of PV panel 1 recorded after 10 minutes. As seen in Fig. 8, the hot and cold spot are now clearly visible. The estimated size of defect and, thus, loss in output performance is $18.3 \% \pm 1.5 \%$. This result is well in line with the results of ST and TRT under indoor environmental

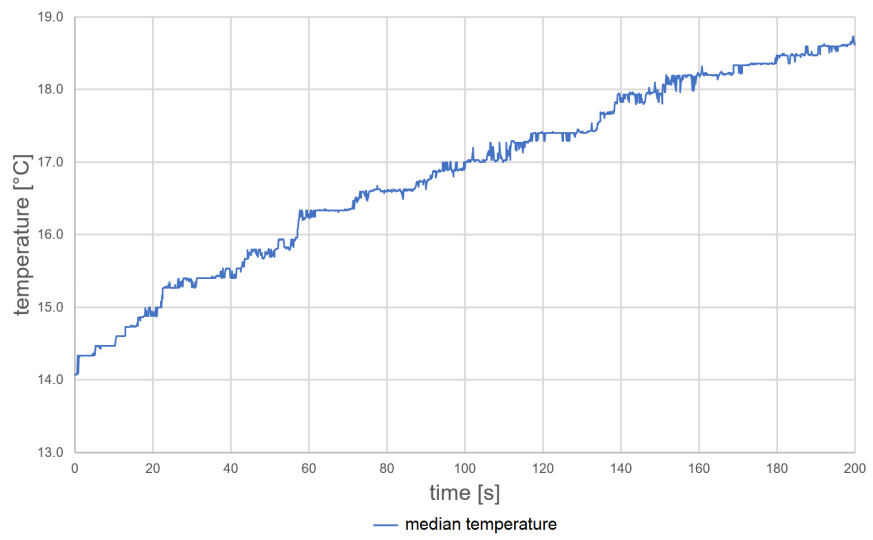

Fig. 6: Progression of the median temperature in PV panel 1

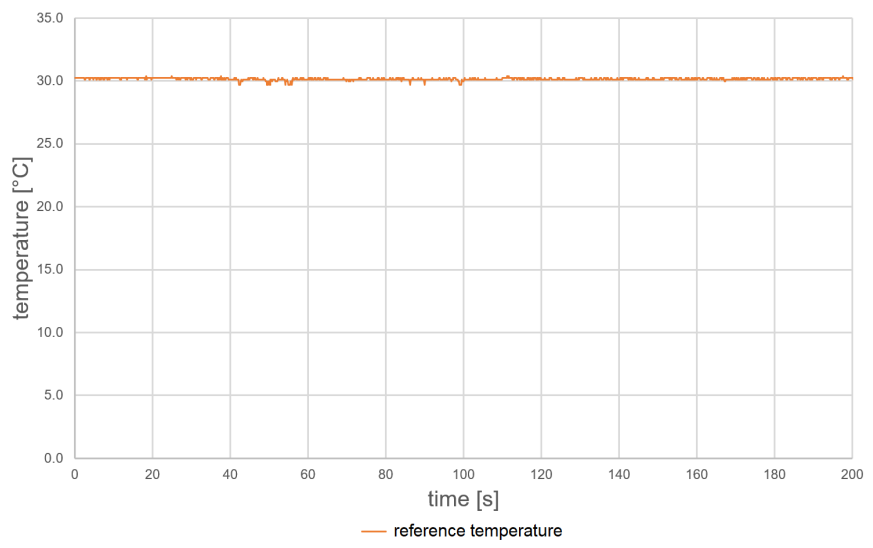

Fig. 7: Progression of the refence temperature

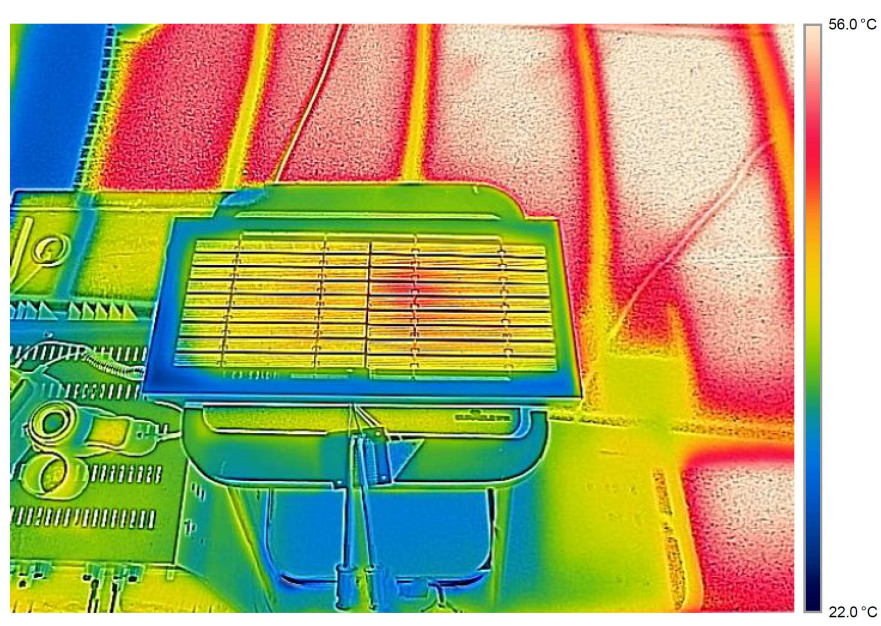

Fig. 8: Thermal image of PV panel 1 after $t=10 \mathrm{~min}$

conditions and electrical measurements. In previous research, the measurement time for ST was set to a specific time for a better comparison of the obtained IR-images of different PV panels [16]. In indoor environments, the measurement time was less than one minute. However, outdoors, this measurement time must be increased substantially and in the order of several minutes. 


\section{DisCUSSION AND CONCLUSION}

PV panels can suffer from various defects and faults due to aging and other factors. As a result, a defect in a single PV cell can occur leading to a decrease in output power of a PV panel and, thus, of an array and an entire PV power plant. Hence, it is critical to detect defects in PV panels and replace them to improve the performance of a PV power plant. Commonly, PV panels are inspected at manufacturing stage to detect defects before PV panels are installed in the field. However, recently, thermal imaging techniques have been proposed to characterise also PV panels which are already installed in the field.

In this paper, we investigated the potential of ST and TRT to characterise PV panels under outdoor environmental conditions, exposed to frequent changes in the solar radiation level. We showed that moderate wind and gust speeds have an impact on IR-image recording such as the size of the ROI, for example. In addition, we concentrated on the use of a portable IR-camera, which can be connected to an Android smartphone, to potentially characterise PV panels which are installed on the top of buildings. Thus, we studied the impact of holding the IR-camera in the hand on the possible usable resolution of the IR-camera.

In experiments, we used the same samples as in previous research to compare measurement results under outdoor environmental conditions which those ones obtained indoors and with the help of electrical verification. We showed the defects in PV cells and panels are clearly visible in the obtained IRimages. Furthermore, the estimated size of the defected area and, thus, the estimated loss in output power correlates with previous measurements and experiments. Hence, ST and TRT are suitable to obtain IR-images in the same accuracy outdoors as indoors. However, in contrast to indoor environments, the heating time of the DUT must be increased significantly.

\section{ACKNOWLEDGMENT}

Dr. Christian Schuss was funded by the Academy of Finland 6Genesis (6G) project (grant no. 318927). Prof. Tapio Fabritius is partially supported by Academy of Finlands FIRI funding (grant no. 320017).

\section{REFERENCES}

[1] Today in Energy. EIA projects world energy consumption will increase $56 \%$ by 2040 . Vol. July. Available https://www.eia.gov/todayinenergy/detail.cfm?Id=12251† [accessed 16 September 2019], 2013.

[2] D.P. van Vuuren, N. Nakicenovic, K. Riahi, A. Brew-Hammond, D. Kammen, V. Modi, and K. Smith, "An energy vision: The transformation towards sustainability - interconnected challenges and solutions", Current Opinion in Environmental Sustainability, vol. 4, issue: 1, 2012, pp. 18-34.

[3] S. Mekhilef, R. Saidur, and A. Safari, "A review on solar energy use in industries", Renewable and Sustainable Energy Reviews, vol. 15, issue: 4, pp. 1777-1790, 2011.

[4] S. Hamou, S. Zine, and R. Abdellah, "Efficiency of PV module under real working conditions", Energy Procedia, vol. 50, pp. 553-558, 2014.

[5] G.J.-P. Tevi, M.É. Faye, M. Sene, I. Faye, U. Blieske, A. Seidou Maiga, "Solar Photovoltaic Panels Failures Causing Power Losses: A Review", $7^{\text {th }}$ IEEE International Energy and Sustainability Conference (IESC), pp. $1-9,2018$.
[6] D.C. Jordan, T.J.Silverman, J.H. Wohlgemuth, S.R. Kurtz, and K.T. VanSant, "Photovoltaic failure and degradation modes", Progress in Photovoltaics: Research and Applications, vol. 25, issue: 4, pp. 318-326, 2017.

[7] W.J. Jamil, H.A. Rahman, S. Shaari, S. and Z. Salam, "Performance degradation of photovoltaic power system: Review on mitigation methods", Renewable and Sustainable Energy Reviews, vol. 67, pp. 876-891, 2017.

[8] A. Triki-Lahiani, A.B.B. Abdelghani, and I. Slama-Belkhodja, "Fault detection and monitoring systems for photovoltaic installations: A review", Renewable and Sustainable Energy Reviews, vol. 82, pp. 2680-2692, 2018.

[9] M.G. Villalva, J.R. Gazoli, and E.R. Filho, "Comprehensive Approach to Modeling and Simulation of Photovoltaic Arrays", IEEE Transactions on Power Electronics, vol. 24, issue: 5, pp. 1198-1208, 2009.

[10] L. Cristaldi, M. Faifer, M. Rossi, and F. Ponci, "A Simple Photovoltaic Panel Model: Characterization Procedure and Evaluation of the Role of Environmental Measurements", IEEE Transactions on Instrumentation and Measurement, vol. 61, issue: 10, pp. 2632-2641, 2012.

[11] C. Schuss, B. Eichberger, and T. Rahkonen, "Measurement and Verification of Photovoltaic (PV) Simulation Models", Proceedings of the IEEE International Instrumentation and Measurement Technology Conference (I2MTC), pp. 188-193, 2013.

[12] J.A. Tsanakas, L. Ha, and C. Buerhop, "Faults and infrared thermographic diagnosis in operating c-Si photovoltaic modules: A review of research and future challenges", Renewable and sustainable energy reviews, vol. 62, pp. 695-709, 2016.

[13] O. Breitenstein, "Nondestructive local analysis of current-voltage characteristics of solar cells by lock-in thermography", Solar Energy Materials and Solar Cells, vol. 95, issue: 10, pp. 2933-2936, 2011.

[14] O. Breitenstein, "Local efficiency analysis of solar cells based on lock-in thermography", Solar Energy Materials and Solar Cells, vol. 107, 2012, pp. 381-389.

[15] Z. Hameiri, A. Mahboubi Soufiani, M.K. Juhl, L. Jiang, F. Huang, Y.-B. Cheng, H. Kampwerth, J.W. Weber, M.A. Green, and T. Trupke, "Photoluminescence and electroluminescence imaging of perovskite solar cells", Progress in Photovoltaics: Research and Applications, vol. 23, issue: 12, pp. 1697-1705, 2015.

[16] C. Schuss, K. Leppnen, K. Remes, J. Saarela, T. Fabritius, B. Eichberger, and T. Rahkonen, "Detecting Defects in Photovoltaic Cells and Panels and Evaluating the Impact on Output Performances", IEEE Transactions on Instrumentation and Measurement, vol. 65, no. 5, pp. 1108-1119, 2016.

[17] C. Schuss, K. Remes, K. Leppnen, J. Saarela, T. Fabritius, B. Eichberger, and T. Rahkonen, "Detecting Defects in Photovoltaic Panels With the Help of Synchronized Thermography", IEEE Transactions on Instrumentation and Measurement, vol. 67, no. 5, pp. 1178-1186, 2018.

[18] M.W. Akram, G. Li, Y. Jin, X. Chen, C. Zhu, X. Zhao, M. Aleem, and A. Ahmad, "Improved outdoor thermography and processing of infrared images for defect detection in PV modules", Solar Energy, vol. 190, pp. 549-560, 2019

[19] J. Teubner, C. Buerhop, T. Pickel, J. Hauch, C. Camus, and C.J. Brabec, "Quantitative assessment of the power loss of silicon PV modules by IR thermography and its dependence on datafiltering criteria", Progress in Photovoltaics: Research and Applications, vol. 27, issue: 10, pp.856-868, 2019.

[20] G. Cipriani, V. Boscaino, V. Di Dio, F. Cardona, G. Zizzo, and S. Di Caro, S., "Application of Thermographic Techniques for the Detection of Failures on Photovoltaic Modules", IEEE International Conference on Environment and Electrical Engineering and 2019 IEEE Industrial and Commercial Power Systems Europe (EEEIC/I\&CPS Europe), pp. 1$5,2019$.

[21] C. Schuss, K. Remes, K. Leppänen, J. Saarela, T. Fabritius, B. Eichberger, and T. Rahkonen, "Estimating the Impact of Defects in Photovoltaic Cells and Panels", Proceedings of the IEEE International Instrumentation and Measurement Technology Conference (I2MTC), pp. 121-126, 2016 